Etnográfica

Revista do Centro em Rede de Investigação em

Antropologia

vol. 16 (3) | 2012

Vol. 16 (3)

\title{
Diálogos entre textos e contextos etnográficos
}

Dialogues between ethnographic texts and contexts

\section{Fernando Florêncio}

\section{OpenEdition \\ Journals}

\section{Edição electrónica}

URL: https://journals.openedition.org/etnografica/2136

DOI: 10.4000/etnografica.2136

ISSN: 2182-2891

\section{Editora}

Centro em Rede de Investigação em Antropologia

\section{Edição impressa}

Data de publição: 1 outubro 2012

Paginação: 619-624

ISSN: 0873-6561

\section{Refêrencia eletrónica}

Fernando Florêncio, «Diálogos entre textos e contextos etnográficos», Etnográfica [Online], vol. 16 (3) I 2012, posto online no dia 08 outubro 2012, consultado o 12 fevereiro 2022. URL: http:// journals.openedition.org/etnografica/2136 ; DOI: https://doi.org/10.4000/etnografica.2136

\section{(c) (i) (9)}

Etnográfica is licensed under a Creative Commons Attribution-NonCommercial 4.0 International License. 


\section{Diálogos entre textos e contextos etnográficos}

\section{Fernando Florêncio}

A partir de experiências de terreno do autor, a produção etnográfica é interpretada enquanto diálogo, ou encontro, de intersubjetividades, entre o etnógrafo e os seus interlocutores, no qual se vão reconstruindo e partilhando, mutuamente, entendimentos e categorizações do contexto social que se estuda.

PALAVRAS-CHAVE: experiência etnográfica, imprevistos, intersubjetividade, mutualidade.

Dialogues between ethnographic texts and contexts - Based on personal fieldwork experiences of the author, the ethnographic work is interpreted as an inter-subjective dialogue, or encounter, between ethnographer and informants, in which meanings and social categorizations of the social context are mutually reconstructed and shared.

KEYWORDS: ethnographic experience, inter-subjectivity, mutuality, unpredictable events.

FLORÊNCIO, Fernando (fjpf@ci.uc.pt) - Centro em Rede de Investigação em Antropologia, Universidade de Coimbra, Portugal.

ESTE TEXTO DERIVA INICIALMENTE DE UMA PARTICIPAÇÃO MINHA no painel "Imprevistos e imponderáveis: condições de produção da etnografia na antropologia contemporânea", no Congresso da Associação Portuguesa de Antropologia, de 2009, e no qual participei enquanto debatedor das comunicações apresentadas. Daí nasceu o convite para participar neste dossiê. Inicialmente, a tarefa parecia-me fácil, bastava encontrar as "notas de campo" retiradas durante o evento e escrever um texto, a partir desses rascunhos. Contudo, tal como na etnografia, o propósito inicial rapidamente se mostrou desajustado, e a realidade mais complexa. Os textos do dossiê evoluíram e transformaram-se, face às comunicações iniciais, e as "notas de campo" eclipsaram-se para um algures não identificável. Face a este "imprevisto" decidi-me por um texto dialogante com os outros, a partir também da minha própria experiência de terreno, partilhando com e a partir deles uma pequena reflexão. Ou seja, não pretendo dialogar, pelo menos diretamente, com outras literaturas senão as deste dossiê. 
A montante surge, necessariamente, a proposição dos organizadores, que partilham com João de Pina-Cabral a ideia de que "a origem do projeto de conhecimento antropológico assenta num processo de procura de pontos de contacto e de sentido que nos aproximam dos nossos interlocutores, ainda que procure a compreensão da diferença (uma marca incontornável da antropologia)" (Viegas e Mapril, neste dossiê). Ou seja, pretendia-se compreender a produção etnográfica não somente como processo subjetivo experiencial do etnógrafo, mas enquanto diálogo, ou encontro, de intersubjetividades, entre o etnógrafo e os seus interlocutores, num processo profundamente inter-relacional, no qual se vão reconstruindo e partilhando, mutuamente, entendimentos e categorizações do contexto que se estuda. A partir desta enunciação fundacional, os organizadores lançam um repto aos autores, o de refletirem sobre "imprevistos" ocorridos durante o trabalho de campo, isto é, sobre "uma experiência inesperada por meio da qual tivessem reformulado as perguntas etnográficas" (Viegas e Mapril, neste dossiê).

Explicito então dois eventos "imprevistos" da minha primeira experiência etnográfica, em 1994 em Moçambique, que, por terem sucedido nesse contexto iniciático, acabariam por ter uma importância marcante em todo o meu futuro entendimento antropológico da realidade moçambicana.

$\mathrm{O}$ meu primeiro trabalho de campo decorreu durante a primeira metade do ano de 1994, em Moçambique, no âmbito da dissertação de mestrado em Estudos Africanos. Originalmente, o projeto de dissertação, que teve que ser desenhado ainda em 1992, centrava-se sobre o processo de identificação política entre o movimento da UNITA e a etnia umbundo, do planalto central angolano. E tinha planeado fazer trabalho de campo em meados de 1993. Tal revelou-se impossível, devido ao reacender da guerra civil am Angola após as eleições de 1992. Deste modo, pensei em "transferir" o objeto de estudo para Moçambique, que já tinha alcançado a paz em outubro de 1992. Em certa medida, a literatura produzida sobre as guerras civis angolana e moçambicana apontava para bastantes semelhanças entre os dois contextos, pois em Moçambique também parecia existir uma forte ligação identitária entre o movimento rebelde da Renamo e o grupo étnico Ndau. Deste modo, decidi escolher o distrito do Búzi, por ser uma "zona" Ndau, mas também porque se encontrava relativamente perto, geograficamente, da cidade da Beira. Pretendia então compreender as causas constitutivas dessa relação. Por outro lado, nesse período, a literatura era ainda bastante influenciada por uma corrente de estudos pós-coloniais, profundamente engajada com os movimentos independentistas africanos, anticolonial e mais centrada nas roturas sociais provocadas pelas independências africanas, do que nas linhas de continuidade com os passados coloniais e mesmo pré-coloniais. ${ }^{1}$ Assim, ao mesmo tempo que fui construindo

l Apesar de tudo, nessa literatura já despontavam na época autores (Geffray, Yáñez-Casal, Roesh, Cahen, entre outros) que se desviavam da "linha frelimista", e explicavam a guerra civil [continua] 
uma visão teórica sobre o assunto, fui consolidando, também muito por influência dessa literatura, uma visão ideológica anticolonial. Ou seja, uma "ideo-logia" pós-colonial.

Não foi pois com espanto, ou estranheza, que escutei as constantes culpabilizações do passado colonial português em Moçambique, com que os meus colegas, moçambicanos, estrangeiros, e outros indivíduos da capital, explicavam as dificuldades do desenvolvimento do país, devido às condições deixadas pelo colonialismo, e mesmo às causas da guerra civil, pelo apoio que os colonos portugueses, radicados após a independência na então Rodésia do Sul, deram à Renamo. Não só não estranhei, como partilhei quase na íntegra dessa visão.

Depois de uma estada de cerca de um mês na capital, no início de fevereiro parti para o Búzi e por lá permaneci até meados de junho. Fui o primeiro estrangeiro a realizar uma investigação, com uma estadia significativa, de mais do que escassas semanas, na região Ndau, e fui o primeiro português a instalar-se no distrito do Búzi desde 1975. Nas zonas mais isoladas do distrito, nomeadamente nas zonas controladas pela Renamo, as crianças gritavam muzungu (branco, estrangeiro) quando me viam, e fugiam, porque nunca tinham visto um branco. Mesmo na família com que convivi todo esse tempo, fui sempre o objeto predileto da diferença, para as crianças, pela cor da pele, mas sobretudo pelo cabelo.

A entrada no terreno careceu de autorizações burocráticas estatais, pelo que a minha chegada à vila do Búzi, sede do distrito, e os primeiros dias de estadia foram marcados por uma excessiva aproximação/dependência dos funcionários locais do Estado, que eram ao mesmo tempo membros do partido Frelimo. De mais a mais, o então administrador distrital tinha cursado uma licenciatura em Coimbra, "ironia do destino". ${ }^{2}$ Passeava-me ele, então, pela vila, apresentando-me a todos como colega da universidade em Portugal, tentando assim reforçar mais a sua escassa legitimidade de dirigente local. ${ }^{3}$ Num contexto político profundamente dominado pela Renamo, esta minha proximidade inicial dos membros do Estado-Frelimo rapidamente me identificou com este partido, sendo comummente olhado com desconfiança pelos dirigentes locais da Renamo, ${ }^{4}$ que se recusaram a falar comigo durante algum tempo.

e o subdesenvolvimento do país, não somente pelo facto colonial, mas também pelas políticas de socialização rural implantadas pelo Estado-Frelimo nos primeiros anos da independência.

2 Em 1994 não fazia nenhuma ideia de que o meu percurso académico me faria ingressar na Universidade de Coimbra, em 2001.

3 A Renamo era a força maioritária no distrito, obteve cerca de $80 \%$ dos votos nas eleições de 1994 , mas o aparelho estatal era hegemonicamente dominado pelo partido Frelimo, o que provocava sérios problemas de legitimidade política aos escassos membros deste partido no distrito, quase todos eles em funções na administração distrital e nas organizações do partido Frelimo.

4 Claro que para tal também muito contribuiu a minha ingenuidade e impreparação para aquela primeira experiência de terreno, pois o facto de ter chegado a um contexto recém-saído de uma guerra civil, de cabelo rapado, e municiado de vasto equipamento militar (botas, cantil, mochila e parca, por exemplo), convencido da sua utilidade para enfrentar as agruras do "mato" e do clima [continua] 
As primeiras conversas de terreno foram então com os elementos da Frelimo, ou com população da sede do distrito por eles indicada. E, "naturalmente", a visão oficial da história de Moçambique produzida pela Frelimo foi desfilando. As explicações "oficiais" anticoloniais e antiportuguesas para o atraso no desenvolvimento do país e para o surgimento dos "rebeldes armados", e da "guerra de agressão", tornaram-se pois hegemónicas.

Foi o Magaço, assistente-intérprete que tinha sido escolhido pelo administrador, por ser o responsável distrital da Frelimo, quem me conduziu ao meu primeiro "imprevisto". ${ }^{5}$ Ao final de vários dias disse-me que eu devia falar com um "mais velho" e agendou uma conversa com um chefe de bairro. Quando o entrevistei, e depois da inicial introdução e apresentação mútua, comecei a inquiri-lo sobre a vida na aldeia no tempo colonial. Perguntou-me então de que tempo colonial estava eu a falar, ao que retorqui, surpreendido: "Do tempo dos portugueses". "Hum... é porque nós fomos colonizados três vezes". Explicou-me de seguida que os vaNdau tinham sido colonizados primeiro pelos "Shanganas da África do Sul", depois pelos portugueses e agora (depois da independência) pelos "Shanganas da Frelimo". ${ }^{6}$

Esta interpretação da história Ndau deixou-me surpreendido. Nessa altura, a surpresa levou-me não à descoberta de conhecimento, mas a refugiar-me no contexto explicativo da relação destas autoridades tradicionais com o Estado colonial que foram depois depostas pela Frelimo, após a independência, e provavelmente teriam "simpatias" pela Renamo. ${ }^{7}$ Contudo, à medida que o tempo de estadia foi passando, voltei a escutar o mesmo, por outros informantes, e noutras regiões do distrito. Esta sucessão de acontecimentos desfazia o caráter essencialmente individualista que eu tinha atribuído inicialmente à minha explicação, além de que muitos destes informantes nem sequer tinham desempenhado nenhum cargo para o Estado colonial. Esta teria que ser então uma interpretação émica da história Ndau, com um cariz sociológico mais profundo.

[continuação] africano, não ajudou a convencer as pessoas de que eu era um universitário português a realizar uma investigação científica apartidária e neutral. Pelo contrário, durante semanas, os dirigentes da Renamo julgavam-me um conselheiro militar da Frelimo.

5 O Magaço rapidamente se tornou mais do que tudo um amigo, com quem partilhei todo o tempo de estadia no Búzi. Apesar de estar ligado à administração distrital, como responsável da cultura, e ser membro da Frelimo, depressa me demostrou que essa ligação era essencialmente instrumental, e que era bastante crítico dos dois partidos. Foi muito graças a ele que me pude introduzir nos diferentes grupos sociais no distrito. Infelizmente, a nossa relação terminou depois dessa pesquisa, por dificuldades várias, e quando em 2001 regressei ao Búzi, já ele tinha falecido.

6 Os vaNdau foram subjugados, entre a década de 30 e a de 90 do século XIX, pelos Nguni, que invadiram o centro e o sul de Moçambique. Para os vaNdau, os Shanganas, do Sul de Moçambique, são os descendentes desses Ngunis.

7 A esmagadora maioria das autoridades tradicionais Ndau tinha fortes "simpatias" pela Renamo, pelo que esta explicação se me afigurava profundamente plausível. 
O segundo "imprevisto" aconteceu poucas semanas depois, quando eu já vivia numa região mais interior do distrito, perto da localidade de Bândua. Um sábado, alguns vizinhos do sr. Menje vieram visitar-nos, para conhecerem o "branco" que estava lá a viver. Não só manifestavam contentamento pela minha presença, e por ter escolhido "viver" ali, como pareciam entender esse facto como o prelúdio da chegada de mais portugueses - de tal modo que, variadíssimas vezes, me perguntaram: "Quando volta o patrão português?" E contavam-me como a vida era muito melhor no "tempo dos portugueses", porque não havia fome, não havia guerra, e havia dinheiro e trabalho.

Uns dias mais tarde, um senhor, talvez com os seus 55-60 anos e cuja identidade não registei, encontrou-me com o Magaço e fez questão de me levar a sua casa para me mostrar os papéis que o "patrão" português lhe tinha deixado. O episódio tem até o seu quê de caricato. Quando me viu, perguntou-me se, sendo eu português, vinha de Portugal. Perante a minha afirmativa, perguntou-me se conhecia o senhor Gouveia e os seus filhos, e se sabia quando é que eles regressariam. Ficou espantado quando eu disse que não, pois o senhor Gouveia também era português e tinha regressado a Portugal, depois de a Frelimo tomar conta de Moçambique, sendo estranho, segundo ele, que eu não o conhecesse. Percebi depois que o tal Gouveia era um dos muitos canavieiros portugueses que vivia no Búzi, que saiu após a independência, e que lhe teria deixado a guardar um maço de papéis, a casa e o canavial, com a promessa de "um dia regressar". Pedia-me então o senhor que eu transmitisse ao senhor Gouveia que ele não tinha conseguido guardar a casa e as terras, porque a Frelimo "levara tudo" (nacionalizara), mas que os papéis estavam seguros.

Não posso aqui entrar em delongas explicativas sobre estes acontecimentos, que se entrecruzam. Muito esquematicamente, posso dizer que eles fazem parte de um universo explicativo da história do grupo Ndau, pois encontrei estas "visões" noutras regiões nos trabalhos de campo de 2000 e 2001 , e que me pareceu que eram partilhadas sobretudo pelos "mais velhos". ${ }^{8}$ No entanto, tal como sublinha Humberto Martins a propósito dos "seus imprevistos", estas situações obrigaram-me a recentrar a minha análise num quadro de referências locais, não universalmente partilhadas, é certo, mas que não encontrava na literatura. Nesse sentido, a etnografia permitiu-me imergir num universo de experiências e de memórias que formavam significados coletivos, aos quais

8 O dito "tempo dos portugueses", na verdade, correspondia ao período final do colonialismo, ao seja, ao período pós-1961, com o fim do estatuto do indigenato, do trabalho forçado e das culturas obrigatórias. Os "mais velhos", mesmo mais velhos, ainda guardavam as memórias da experiência colonial do estatuto de indígena, do trabalho forçado (chibalo) e da cultura obrigatória do algodão. A valorização positiva desse período resulta, essencialmente, da comparação com o período da independência, marcado pelos impactes negativos que a política de socialização rural implantada pela Frelimo teve nos modelos de reprodução social camponeses, acrescida das memórias históricas profundamente negativas que os vaNdau têm do período de dominação Nguni. 
penso que fui tendo acesso pela partilha conjunta de visões do mundo, em prolongados momentos de convivencialidade. Rapidamente me apercebi de que essa partilha constituía uma exigência dos outros para comigo, questionando-me, por vezes interminavelmente, sobre o que eu pensava do ato colonial e da atualidade moçambicana, ou seja, numa relação de mutualidade na qual fui tecendo um conhecimento que, sendo científico, não deixa igualmente de ser ideológico. O terreno demonstrou-me que essa exigência acontece mesmo quando o antropólogo se encontra numa suposta posição social superior à dos seus informantes. Nesse âmbito, os meus interlocutores não confrontavam um método científico de produzir conhecimento, ao contrário do que descreve Madalena Patriarca no seu texto, mas o próprio conhecimento.

Concluo então com um comentário que reflete estas minhas experiências, ao mesmo tempo que integra as minhas leituras sobre os textos deste dossiê. Primeiro e de forma genérica, revejo-me na ambiguidade do lugar do antropólogo de que falam os autores, e nesse sentido parece-me que o conjunto de textos identifica importantes aspetos da relação, que não é apenas e nem principalmente uma experiência pessoal decorrente da etnografia, mas um procedimento fundamentalmente metodológico ou, como se sugere na introdução, epistemológico. Quase todos discorrendo sobre a ambiguidade de uma posição de interioridade-exterioridade que o antropólogo vive na experiência etnográfica - espécie de condição de in between and in betwixt - que é preciso negociar constantemente, o conjunto dos textos retrata/reflete uma situação que os casos que relatei também refletem. Recordo as duas expressões com que amiúde me designavam: "patrão branco" e muzungu. A primeira, convocando-me para uma proximidade, ou intimidade, é feita de uma "história partilhada" entre portugueses e vaNdau, e usualmente usada como manifestação de "quem sabe do que fala". ${ }^{9}$ A segunda, usada quase sempre pejorativamente, realça não somente a exterioridade, o "tu não és daqui" que Humberto Martins torna o mote de reflexão, mas sobretudo exaltando-a, como se se tratasse de expurgar e demonizar um passado que o presente parecia reavivar.

Confesso-me, para fechar, um antropólogo amante da etnografia, sem pudor e sem a desconsiderar como uma "arte menor", contrariamente ao que postulou Dan Sperber e que tanta escola fez. Entendo a etnografia como o "laboratório" do antropólogo e da antropologia. Entendo-a, apropriando-me da expressão de Pina Cabral, usada por Viegas e Mapril, na introdução a este dossiê, como um lugar de "revelações partilhadas". A episteme da etnografia não é para mim o conhecimento do outro, mas o conhecimento sobre o outro, com o outro.

9 O régulo de Chaiva, no distrito de Mossurize, disse-me uma vez que eu era o "branco mais Ndau que ele conhecia". 